\title{
THE BALANCE OF NATURE-WHAT DOES IT MEAN?
}

\section{By G. Dennlen De la Tour}

Maintaining the balance of nature means keeping up the jiological equilibrium ; that is the quantitative balance between iving beings, animals and plants. The term should refer to an urea which can be defined fairly clearly, preferably from a biological standpoint.

Primitive man is part of nature and does not disturb the biological equilibrium. Civilized man breaks it whenever he enters into virgin nature; be it by the exploitation of forests, by agriculture, by cattle breeding, by the introduction of an sxotic species or by other levies upon nature. Breaking this balance also means disturbing the ecological conditions. The " home" is being disturbed when the environment is changed by the elimination or heavy decrease of one of its animal or plant inhabitants. This disturbance reverberates upon the other inhabitants and sometimes affects again the environment itself.

Protectionists try to re-establish the broken biological equilibrium and almost cvery measure to protect a species has this as part of its intention. Literally speaking the balance of nature can only be maintained in a place which civilized man has not yet exploited and where he has decided to forego exploitation. Most national parks in the U.S.A. are examples of this. In other areas, such as the Kruger National Park, man may decide to re-establish an equilibrium which has been broken.

In all other cases plant and animal ecology give way to the demands of human ecology. The broken biological equilibrium which follows leads to a fluctuating state which may end in disaster even for man. An equilibrium must again be established but it will be a new one adapted to human ecology, consequently I call it human ecological equilibrium. There is nothing new about this-it has been practised for many centuries in Europe and Asia and for decades in America, Africa and Australia. Only the definition is new. 